\title{
Research on Data Ownership of Power Grid Enterprises
}

\author{
Liyu Xia ${ }^{1, *}$, Wan $\mathrm{He}^{1}$, Jin Liu ${ }^{1}$, Wenhao Zhu ${ }^{1}$, Jian Zhao ${ }^{1}, \mathrm{Xianghai} \mathrm{Xu}^{2}$ \\ ${ }^{1}$ State Grid Energy Research Institute \\ ${ }^{2}$ State Grid Zhejiang Electric Power Company Hangzhou Power Supply Company \\ ${ }^{*}$ Corresponding author. Email: xialiyu@sgeri.sgcc.com.cn
}

\begin{abstract}
Power data is an important way for power grid enterprises to serve the party, the state, society and people's livelihood. In order to promote the asset operation of power data, the urgency of defining power data ownership continues to improve. Based on the theoretical and practical results of data ownership, this paper divides the data types of power grid enterprises into three categories: personal data, enterprise data and public data. This paper puts forward that power grid enterprises should follow the principle of "respecting the basic rights of customers and focusing on the legitimate rights and interests of enterprises" to strengthen the protection of national core data and important industrial data. Power grid enterprises should also transfer the control right, use right and income right of customer data to the enterprise by signing a privacy agreement.
\end{abstract}

Keywords: Power data, Ownership theory, Data classification, Ownership definition.

\section{INTRODUCTION}

The purpose of determining data ownership is to balance the rights and interests of all participants in the whole life cycle of data ${ }^{[1]}$, realize the incentive compatibility of all stakeholders, and promote the reasonable and orderly flow of data. With the germination and development of China's data element market, academia and industry have carried out a series of discussions on enterprise data ownership ${ }^{[2]}$. Due to the complexity of the problem itself and the diversity of conceptual understanding, many views have been formed on the discussion of data ownership ${ }^{[3]}$.

At present, many viewpoints have been formed on the discussion of the nature of enterprise data rights and data ownership, including object negation theory, enterprise original acquisition theory, data asset theory, new data property right theory, data intellectual property right theory, data utilization criterion theory, data property right typology theory, ownership+usufruct dual structure theory, etc ${ }^{[4,5]}$. In terms of legal practice, on June 29, 2021, the second meeting of the Standing Committee of the seventh Shenzhen Municipal People's Congress voted and adopted the data regulations of Shenzhen Special Economic Zone, which put forward the concept of "data rights and interests" at the legislative level for the first time, and made it clear that natural persons enjoy personality rights and interests in personal data according to law, including informed consent, supplementary correction, deletion, access and reproduction; Natural persons, legal persons and unincorporated organizations enjoy the property rights and interests stipulated in laws, administrative regulations and these regulations for the data products and services formed by their legal processing of data, and can independently use, obtain income and dispose of them according to law.

Generally speaking, the academic discussion and industry practice on data ownership have basically reached the following consensus. First, the multiple attributes and complex rights and obligations of data make it difficult to make a single arrangement for the ownership of data in general ${ }^{[6]}$. Second, the legal relationship of personal data protection is relatively clear, and the open sharing of government data has become a consensus. Third, for enterprise data, in recent years, the judicial field has protected the interests of enterprise data ownership through the application of competition law, forming a positive market incentive in the data field. Fourth, the core of discussing the data ownership of enterprises is to clarify the interests of enterprise data ownership and encourage continuous investment in the data field ${ }^{[7]}$. 


\section{DATA TYPE DIVISION OF POWER GRID ENTERPRISES}

According to different classification standards and value judgments, the data managed by power grid enterprises can be divided into personal data, enterprise data and public data, sensitive data and non sensitive data, original data and derived data, etc. the classification method of power grid enterprise data needs to be determined according to the needs of data ownership research. Among them, it is difficult to determine the classification standard of sensitive data and non sensitive data, and the use of this classification will increase the complexity of the research on data right confirmation. Both original data and derivative data contain personal information, enterprise customer information and other contents, and the corresponding legal regulation scope is scattered. Using this classification, it is still necessary to classify the original data and derivative data respectively. According to different data subjects, it is divided into personal data, enterprise data and public data. It can correspond personal data to the field of personal information protection, enterprise data to the field of classified information protection and public data to the field of government data opening. The data division standard is clear and the scope of legal regulation is clear, According to the subject classification, it is applicable to the research on the confirmation of corporate data rights.

Personal data refers to the data that can identify the identity of natural persons or the data generated by the behavior of natural persons, including the unique characteristic data of natural persons and the behavior data of participating in economic and social activities. The personal data of power grid enterprises includes customer personal data and employee personal data. Among them, customer personal data is the customer's personal identity information and power consumption behavior information obtained through online methods such as wireless private network, enterprise app and official website, and offline methods such as business hall power office and manual door-to-door meter reading. Employee personal data refers to the personal identity information of employees collected online or offline in the process of human resource management by power grid enterprises, as well as the operation log information retained by employees in the enterprise information system during their daily work.

Enterprise data refers to all kinds of data generated or legally obtained and actually controlled by an enterprise in production, operation and management activities, including enterprise entity data and enterprise customer data authorized by users. The enterprise data of power grid enterprises include their own data, customer authorization data and platform service data. Among them, the enterprise's own data is enterprise's basic information and operation management data accumulated on the collaborative office system, online state grid and other information systems or departmental paper materials in the daily management process of the enterprise as the main body. Customer authorization data refers to the customer enterprise data and power consumption behavior data accumulated through the authorization of enterprise customers in the process of operating various businesses and providing various services, as well as the customer derived data obtained from the processing and production of customer enterprise data. Platform service data refers to the comprehensive energy platform, smart car networking upstream and downstream enterprise data or customer data of the industrial chain managed or used in the process of new energy cloud and other platforms.

Public data refers to all kinds of data and their derived data collected by the government or public institutions in carrying out activities according to law, such as economic and social data, environmental meteorological data, etc. The public data of power grid enterprises include government affairs disclosure data and public attribute data. Government affairs disclosure data is the data of various social subjects and their related activities that government departments actively open to the society in the process of social management in order to improve the level of public services and promote the construction of administrative transparency. Public attribute data is controlled by enterprises, which is of great significance to government management and social governance, and is beneficial to supporting the government to make administrative decisions scientifically and comprehensively and respond to the needs of all social parties.

\section{DEFINITION OF DATA OWNERSHIP OF POWER GRID ENTERPRISES}

Combined with the research status of data ownership theory and practice in China, defining the data ownership of power grid enterprises should balance the tension between data ownership and data utilization, follow the principle of "respecting the basic rights of customers and focusing on the legitimate rights and interests of enterprises". That is, fully respect the basic data rights of individual subjects or enterprise subjects. Based on the large amount of capital and labor costs invested in the accumulation of original data, the development of derivative data and the construction of data platform during the operation of power grid enterprises. Focusing on the legitimate commercial rights and interests of enterprise management and use of data. 


\subsection{Personal data ownership}

The personal data of power grid enterprises involves personal privacy, and its basic rights belong to individuals. The Civil Code stipulates in the general part that the personal information of natural persons is protected by law (Article 111), establishes the personality right part, and a special chapter stipulates "the right to privacy and personal information protection", which not only clearly defines the scope of personal information (article 1034), but also stipulates the principles and conditions that should be followed in dealing with personal information (articles 1035 and 1036) Constructing the framework of basic rights and obligations between natural persons and information processors (articles 1037-1039), etc. The personal information protection law (draft of the second review) clearly states that "individuals have the right to dispose of personal data." in the process of processing personal data, the information subject exercises instrumental rights such as the right to informed consent, the right to copy and the right to delete. Giving the data base right to the original customer or employee of personal data is a manifestation of respecting the source of data rights. As the main body of data, individual customers and employees can choose to transfer part of the rights of private data to the enterprise or society, so as to enjoy more high-quality services and promote the optimal allocation of data resources.

Power grid enterprises shall, based on the basic principle of "Notification+consent", transfer the personal data control right, use right and income right of customers or employees to enterprises by signing privacy agreements. If an individual, as the owner of the original basic data, explicitly agrees that the enterprise collects and uses its personal data, when the enterprise obtains economic or other benefits through the above personal data, the individual customers or employees should also enjoy part of the data benefits. Among them, data revenue sharing methods can be flexible and diverse, including explicit benefits such as monetary reward or electricity tariff reduction, or implicit benefits such as free value-added services. The transfer of some rights allows the enterprise to process, control and research and develop employees' personal data, which not only respects the enterprise's contribution to data management, but also increases the individual explicit benefit or implicit utility.

\subsection{Enterprise data ownership}

As to enterprise data of power grid enterprises, the basic rights of their own data belong to the enterprise, the original enterprise data basic rights of customer authorization and platform services belong to external enterprises, and the basic rights of derivative enterprise data desensitized or generated after processing belong to the enterprise. Both the enterprise itself and its customers belong to the civil subjects stipulated in the civil code, and enjoy the basic rights similar to personal data for their own data necessary for their own business activities and their own original generated data. The remarkable characteristics of enterprise data different from personal data are: enterprise data is generated by production and business activities, while personal data is proprietary to natural persons. The basic rights of enterprise data can often be transferred, while personal data can be applied, but the basic rights cannot be exchanged. Enterprise data often involves state secrets or enterprise secrets. China has established a basic framework for the protection of state secrets through the law on the protection of state secrets and the supporting system regulations on the implementation of the law on the protection of state secrets, and has made major provisions on trade secrets through the anti unfair competition law. The law on Guarding State secrets stipulates that "all state organs, armed forces, political parties, social organizations, enterprises, institutions and citizens have the obligation to keep state secrets. Any act endangering the security of state secrets must be investigated by law" (Article 3). The anti unfair competition law stipulates that "Business operators shall not disclose, use or allow others to use the business secrets they have in their possession in violation of their confidentiality obligations or the requirements of obligees for keeping business secrets" (Article 9).

Power grid enterprises shall strengthen the protection of national core data and important industrial data, and "inform+agree" As the basic principle, the control right, use right and profit right of customer authorized data and platform service data are transferred to the enterprise by signing an agreement. Some power dispatching data, equipment operation and maintenance and other data accumulated by power grid enterprises in the process of carrying out power grid business belong to the category of data state secrets, which is the data security law National core data or important data of the power industry. Enterprises applying classified data in China must take protecting data security as the bottom line and red line, and must abide by the law on Guarding State secrets and the data security law And other laws and regulations, no matter whether the enterprise data is classified or not, it will not be transmitted abroad at present. The original enterprise data collected by enterprises through signing agreements for customer authorization and platform services shall comply with the principle of "unnecessary and not provided" In principle, and has the obligation to protect the managed original enterprise data. For the enterprise data authorized by the agreement, the enterprise can enjoy some control, use and income rights according to the labor contribution cost when carrying out data sorting, storage and analysis. 


\subsection{Public data ownership}

The public data of power grid enterprises has the attribute of public goods, and the government, customers and enterprises enjoy public property rights over public data. Public data involves social and public interests, and its value is reflected in the information it carries. Only by promoting the opening of data to the outside world and making the data fully flow, share and exchange, can the expected agglomeration effect and scale effect be formed. Since the "government data opening campaign", including default opening, machine-readable, timely and interoperable, have become the basic principles of government data opening. In recent years, governments have accelerated the pace of public data opening. In August 2015, the action platform for promoting big data development issued by the State Council clearly pointed out: "Take big data as an important means to improve the government's governance ability, improve the government's decision-making and risk prevention level, and improve the accuracy and effectiveness of social governance by efficiently collecting, effectively integrating and deepening the application of government data and social data." China's opinions on marketoriented allocation system and mechanism, April 2020 In the next step, the state will further clarify the data open directory, build a unified, standardized, interconnected, safe and controllable government data open platform, and promote the utilization of public data.

Power grid enterprises shall take into account the obligation of public data demand cooperation and the responsibility of security and privacy protection, provide data externally on the basis of direct legal authorization, and establish standards to deal with public welfare data collection. As a public utility unit, power grid enterprises have the responsibility to publicly share public data, provide public products and create social benefits without involving personal privacy security and national security public value. Under the trend of government data opening, power data opening is facing higher requirements. Excessive and insufficient public data opening may lead to the risk of improper performance of legal obligations. At present, China's data security law only authorizes public security organs and national security organs to access enterprise data for the needs of maintaining national security or investigating crimes according to law. For the statutory situation of data provided by a system enterprise, the enterprise does not have the obligation to open the data for the needs of a large number of non statutory organs to obtain the data. The enterprise needs to establish a standardized process to review the name, purpose and purpose, type and scope, rationality and necessity of the unit obtaining the data, so as to formally ensure that the open data is used to serve the public interest and reduce the risk Low risk of data opening.

\section{CONCLUSION}

Power data is naturally an important data field related to people's livelihood and an important way for power grid enterprises to serve the party, the state, society and people's livelihood. The urgency of defining power data ownership continues to improve. At present, many viewpoints have been formed on the discussion of the nature of enterprise data rights and data ownership. According to different subjects, power data is divided into personal data, enterprise data and public data. It can correspond personal data to the field of personal information protection, enterprise data to the field of classified information protection and public data to the field of government data opening. To define the data ownership of power grid enterprises, we should balance the tension between data ownership and data utilization, follow the principle of "respecting the basic rights of customers and focusing on the legitimate rights and interests of enterprises", strengthen the protection of national core data and important industrial data, and sign privacy agreements to transfer the control, use and income rights of customer data to enterprises.

\section{AUTHORS' CONTRIBUTIONS}

Zhao Jian and $\mathrm{Xu}$ Xianghai wrote the first part, Liu Jin and Zhu Wenhao wrote the second part, and Xia Liyu and he wan wrote the third part

\section{ACKNOWLEDGMENTS}

This paper is a phased achievement of Science and technology projects of State Grid (Research on Key Legal Technologies of Power Data Ownership and Commercial Application, SGZJHZ00HLJS2000265).

\section{REFERENCES}

[1] S. Xixue. Construction of data usufruct system in government data opening, Journal of East China University of political science and law, 2021,24 (04), pp. 59-72

[2] Y. Yi. Research on data ownership and compliance transaction, Wuhan finance, 2021 (05), pp. 82-88

[3] H. Ke, C. Yuezhi, C. Jiaze. Theoretical logic and path design of data right confirmation, Financial science, 2021 (03), pp. 43-55

[4] H. Kai. Allocation rules of personal data ownership in the era of big data, Journal of law, 2021,42 (01), pp. 99-110 
[5] W. Yuanshan. Review and trend prospect of the evolution of data rights in China, Library forum, 2021,41 (01), pp. 119-131

[6] H. Xuzhi. The dilemma and solution of data right confirmation, Oriental Law, 2020 (01), pp. 97-107

[7] Y. Jia. Guidelines for the use of enterprise data, Tsinghua law, 2019,13 (03), pp. 114-125 